\title{
ICAM5 as a Novel Target for Treating Cognitive Impairment in Fragile X Syndrome
}

\author{
Ya-ping Pei, ${ }^{1,2,3 *}$ Yue-yi Wang, ${ }^{1,2,3 *}$ Dan Liu, ${ }^{1,2,3 *}$ Hui-yang Lei, ${ }^{5}$ Zhi-hao Yang, ${ }^{1,2,3}$ Zi-wei Zhang, ${ }^{1,2,3}$ Man Han, ${ }^{1,2,3}$ \\ Ke Cheng, ${ }^{1,2,3}$ Yu-shan Chen, ${ }^{1,2,3}$ Jin-quan $\mathrm{Li}^{1,2,3}$ Gui-rong Cheng, ${ }^{1,2,3}$ Lang $\mathrm{Xu},{ }^{1,2,3}$ Qing-ming $\mathrm{Wu},{ }^{1,2}$ \\ Shawn M. McClintock, ${ }^{1,2,4}$ Ying Yang, ${ }^{5}$ Yong Zhang, ${ }^{6}$ and Yan Zeng ${ }^{1,2,3}$ \\ ${ }^{1}$ Brain Science and Advanced Technology Institute, ${ }^{2}$ Hubei Province Key Laboratory of Occupational Hazard Identification and Control, ${ }^{3}$ Big Data Science \\ and Engineering Research Institute, Wuhan University of Science and Technology, Wuhan 430065, People's Republic of China, ${ }^{4}$ Department of Psychiatry, \\ UT Southwestern Medical Center, Dallas, Texas 75390, ${ }^{5}$ Department of Pathophysiology, School of Basic Medicine and The Collaborative Innovation Center \\ for Brain Science, Key Laboratory of Hubei Province and Ministry of Education of China for Neurological Disorders, Tongji Medical College, Huazhong \\ University of Science and Technology, Wuhan 430030, People's Republic of China, and ${ }^{6}$ Department of Neurobiology, School of Basic Medical Sciences and \\ Neuroscience Research Institute, and Key Laboratory for Neuroscience, Ministry of Education of China and National Committee of Health and Family \\ Planning of China, Peking University, Beijing 100191, People’s Republic of China
}

Fragile X syndrome (FXS) is the most common inherited form of intellectual disability, resulted from the silencing of the Fmr1 gene and the subsequent loss of fragile $\mathrm{X}$ mental retardation protein (FMRP). Spine dysgenesis and cognitive impairment have been extensively characterized in FXS; however, the underlying mechanism remains poorly understood. As an important regulator of spine maturation, intercellular adhesion molecule 5 (ICAM5) mRNA may be one of the targets of FMRP and involved in cognitive impairment in FXS. Here we show that in Fmr1 K0 male mice, ICAM5 was excessively expressed during the late developmental stage, and its expression was negatively correlated with the expression of FMRP and positively related with the morphological abnormalities of dendritic spines. While in vitro reduction of ICAM5 normalized dendritic spine abnormalities in Fmr1 KO neurons, and in vivo knockdown of ICAM5 in the dentate gyrus rescued the impaired spatial and fear memory and anxiety-like behaviors in Fmr1 KO mice, through both granule cell and mossy cell with a relative rate of $1.32 \pm 0.15$. Furthermore, biochemical analyses showed direct binding of FMRP with ICAM5 mRNA, to the coding sequence of ICAM5 mRNA. Together, our study suggests that ICAM5 is one of the targets of FMRP and is implicated in the molecular pathogenesis of FXS. ICAM5 could be a therapeutic target for treating cognitive impairment in FXS.

Key words: cognitive impairment; dendritic spine maturation; FMRP/ICAM5 mRNA interaction; fragile X mental retardation protein; fragile $\mathrm{X}$ syndrome; intercellular adhesion molecule 5

\section{Significance Statement}

Fragile X syndrome (FXS) is characterized by dendritic spine dysgenesis and cognitive dysfunctions, while one of the FMRP latent targets, ICAM5, is well established for contributing both spine maturation and learning performance. In this study, we examined the potential link between ICAM5 mRNA and FMRP in FXS, and further investigated the molecular details and pathological consequences of ICAM5 overexpression. Our results indicate a critical role of ICAM5 in spine maturation and cognitive impairment in FXS and suggest that ICAM5 is a potential molecular target for the development of medication against FXS.

\section{Introduction}

Fragile X syndrome (FXS) is the most common inherited cause of mental retardation, resulted from the transcriptional silencing of the fragile $\mathrm{X}$ mental retardation 1 (Fmrl) gene and the subsequent loss of fragile $\mathrm{X}$ mental retardation protein (FMRP; Davis

Received Oct. 15, 2018; revised Dec. 12, 2019; accepted Dec. 15, 2019.

Author contributions: Q.-m.W., S.M.M., and Y. Zeng designed research;Y.-p.P., Y.-y.W., H.-y.L., Z.-h.Y., Z.-w.Z., M.H., K.C., J.-q.L., G.-r.C., L.X., Y.Y., and Y. Zhang performed research; G.-r.C., L.X., and Y. Zeng contributed unpublished reagents/analytic tools; Y.-p.P., D.L., and Y.-s.C. analyzed data; Y. Zeng wrote the paper. and Broadie, 2017). FXS is characterized by cognitive impairment associated with a broad spectrum of psychiatric comorbidities, including hyperactive behavior, autism spectrum disorder, poor attention, and seizure (Wang et al., 2012; Specchia et al.,

This work was supported by the National Natural Science Foundation of China (Grants 81571095 and 81870901 to Y. Zeng), the Hubei Natural Science Foundation (Grant 2016CFB501 to Y. Zeng), and the Hubei Health and Family Planning Commission (Grant WJ2015MB050 to Y. Zeng). S.M.M. reports honoraria as teaching faculty from TMS Health Solutions.

*Y.-p.P., Y.-y.W., and D.L. are co-first authors.

The authors declare no competing financial interests. 
2017). Currently, there is no effective therapy for treating cognitive impairment in FXS, making the quest for novel targets of considerable importance. A common neuropathologic phenotype seen in FXS is dendritic spine malformation, which is associated with an increased number of long, thin, and tortuous spines, and a pruning failure during spine transition from development to mature ones (Irwin et al., 2001; Portera Cailliau and Yuste, 2001; Wijetunge et al., 2014). Dysgenesis of dendritic spines is also observed in many other neurodevelopmental disorders (NDDs; Irwin et al., 2001; Portera Cailliau and Yuste, 2001; Calabrese et al., 2006; Bourgeron, 2009; Penzes et al., 2011; De Rubeis et al., 2012; Wijetunge et al., 2014). Thus, determining the molecular mechanisms involved in impaired dendritic spine formation and maturation and cognitive impairment may shed light on FXS and other NDDs for the development of new therapeutic strategies.

Under normal conditions, FMRP exists at a high level in dendritic spines (Antar et al., 2005; Davis and Broadie, 2017). Through binding to mRNAs, FMRP regulates the expression of many genes at the post-transcriptional level (Darnell and Klann, 2013; Specchia et al., 2017), including mRNA dendritic localization, axonal/dendritic transport, and export from the nucleus to the cytoplasm (Bassell and Warren, 2008; Melko and Bardoni, 2010; Pasciuto and Bagni, 2014). In the FXS pathological condition, FMRP loss-of-function results in excessive protein synthesis, and further defects in synaptic plasticity, as well as cognitive impairment (Bassell and Warren, 2008; Darnell and Klann, 2013). Over the last 20 years, a large number of potential mRNA targets of FMRP have been found (Brown and Huynh, 2001; Darnell et al., 2011; Ascano et al., 2012). A well known study proposed an underestimated list of 842 mRNA targets of FMRP and also listed a total of 19,493 related complexes, including intercellular adhesion molecule 5 (ICAM5; Darnell et al., 2011). However, the pathological consequences of these mRNA targets remain unclear.

ICAM5 is a cell adhesion molecule that belongs to the Ig superfamily (Yoshihara and Mori, 1994). It is widely expressed in telencephalic neurons and plays an important role in higherorder cognitive and motor functions (Mori et al., 1987; Oka et al., 1990; Mitsui et al., 2007). In the early postnatal life of mammals, the ontogenic appearance of ICAM5 is consistent with the timing of dendritic outgrowth, spine formation, and synaptogenesis, and its expression persists into adulthood (Mori et al., 1987; Yoshihara et al., 1994; Tian et al., 2000). In addition, the cleavage of ICAM5 leads to a reduced density of filopodia via $\beta_{1}$ integrin interaction and the consequent phosphorylation of cofilin (Conant et al., 2011), decreases glutamatergic transmission and neuronal excitability (Niedringhaus et al., 2012), and alters spine maturation and learning performance (Nakamura et al., 2001). These findings suggest that ICAM5 is involved in dendritic spine morphogenesis and synapse development. However, the involvement of ICAM5 in the neuropathology and spine maturation in FXS remains unclear.

In this study, we aim to examine a possible link between ICAM5 and FMRP in FXS, and to further investigate the molecular detail and the pathological consequences. We confirmed that ICAM5 mRNA is a target of FMRP. In the FXS mouse model,

Correspondence should be addressed to Yan Zeng at yanzeng11@foxmail.com.

https://doi.org/10.1523/JNEUROSCI.2626-18.2019 Copyright (C) 2020 Pei et al.

This is an open-access article distributed under the terms of the Creative Commons Attribution License Creative Commons Attribution 4.0 International, which permits unrestricted use, distribution and reproduction in any medium provided that the original work is properly attributed.
ICAM5 expression is aberrantly increased, correlated with the developmental delay of spine maturation and the concomitant cognitive impairment, and the reduction of ICAM5 expression rescues the behavioral disorders in Fmr1 KO mice.

\section{Materials and Methods}

Animals. Fmr1 knock-out (KO; FVB.129P2-Pde6b ${ }^{+} \mathrm{Tyr}^{\mathrm{c}-\mathrm{ch}} \mathrm{Fmr} 1^{\mathrm{tm} 1 \mathrm{Cgr} / \mathrm{J})}$ and wild-type (WT; FVB.129P2-Pde6 $\mathrm{b}^{+} \mathrm{Tyr}^{\mathrm{c}-\mathrm{ch}} / \mathrm{Ant}$ ) ) mice were purchased from The Jackson Laboratory. All procedures that involved animals were performed in accordance with a protocol approved by the Wuhan University of Science and Technology Animal Research Committee. Male mice were used in all experiments.

Western blotting analysis. The protein level from each selected telencephalic region was measured by Western blot analysis, as previously described (Zeng et al., 2012). Primary antibodies used in this study were goat polyclonal anti-ICAM5 (1:1000; catalog \#2507S, Santa Cruz Biotechnology), rabbit polyclonal anti-ICAM5 (1:1000; catalog \#ab232785, Abcam), and rabbit polyclonal anti-FMRP (1:1000; catalog \#4317S, Cell Signaling Technology).

Primary neuron culture, transfection, and morphometrical analysis. Primary mouse neuronal cultures were obtained from the cerebral cortex of embryos [embryonic day 17 (E17) to E18; Hozumi et al., 2003). For neuron transfection, lentiviral vectors were used with $1 \times 10^{8}$ transduction units/ml (multiplicity of infection, 10). To suppress and overexpress FMR1, we used GV118 (Shanghai Genechem) with the target sequence 5'-ACGAAACTTAGTAGGCAAA-3' and the GV303 vector (Shanghai Genechem) with full-length FMR1, respectively. After $24 \mathrm{~h}$ of transfection, the neurons were cultured for $2 \mathrm{~d}$ for protein measurement, and for $8 \mathrm{~d}$ for morphological observation of the dendritic spines. Dil staining was performed as described previously (Cheng et al., 2014), and dendritic spines were examined using an FV1000 confocal microscope (FluoView1000, Olympus). Spine head width and length of dendritic protrusions were measured by ImageJ. Only spines within $100 \mu \mathrm{m}$ cell bodies were evaluated.

Quantitative real-time PCR. We evaluated the mRNA level of FMR1 and ICAM5 in Fmr1 KO versus WT mice by quantitative real-time PCR (qRT-PCR). Total RNA was extracted by Invitrogen TRIzol Reagent (Thermo Fisher Scientific) and subsequently synthesized into single-strand cDNA using Invitrogen Superscript II reverse transcriptase (Thermo Fisher Scientific). The cDNA amplification was performed using SYBR Premix Ex Tap (Tli RNaseH Plus, Takara) on the Bio-Rad CFX96 system (Chen et al., 2018). Genes and forward/reverse primers used for qRT-PCR are as follows: $\beta$-actin: forward, CTCTTTTCCAGCCTTCCTTCTTG; reverse, AGAGGTCTT TACGGATGTCAACG; FMR1: forward, ATCGCTAAT GCCACTGTTCTTT; reverse, CGACCCATTCCTTG ACCATC; ICAM5: forward, AGAACAGGAAGGCACCAAACAG; reverse, CTGG CTCACT CAAAGTCAGAAGAG; and U1 snRNA: forward, GGGAGATACCA TGATC ACGAAGGT; reverse, CCACAAATTATGCA GTCGAGTTT CCC.

Linear sucrose gradient fractionation. Three-week-old mouse hippocampus lysates and neurons were submitted to Panjin Fengrui Bio-Technology and Yusen Biotechnology for ribosome-bound mRNA testing.

Golgi impregnation procedure and spine analysis. The Golgi staining method was performed with the FD Rapid GolgiStain Kit (FD Neurotechnologies) as previously described in studies by Tian et al. (2015) and Gao et al. (2016). Categories of spine morphology were identified as follows: mushroom-shaped spine (spine with a large bulbous head; the diameter of spine head minus the diameter of the spine neck, $\geq 1.5 \mu \mathrm{m}$ ); thin spine (filopodia-like protrusion, diameters of spine and neck are nearly equal, and spine length is greater than spine width); and stubby spine (short spine without a well defined spine neck).

RNA-binding protein immunoprecipitation and RNA immunoprecipitation sequencing cDNA library construction. RNA-binding protein immunoprecipitation (RIP) experiments were conducted using the Magna RIP RNA-Binding Protein Immunoprecipitation Kit (Millipore) according to the manufacturer instructions (Moradi et al., 2016). For RIP-sequencing analysis, two types of biological replicates of total RNA samples were obtained, one from the input group (lysate) and one from the FMRP group 


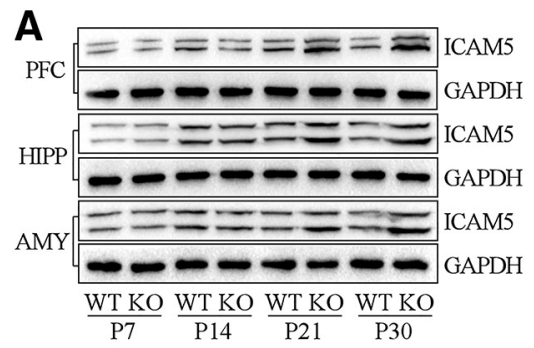

B
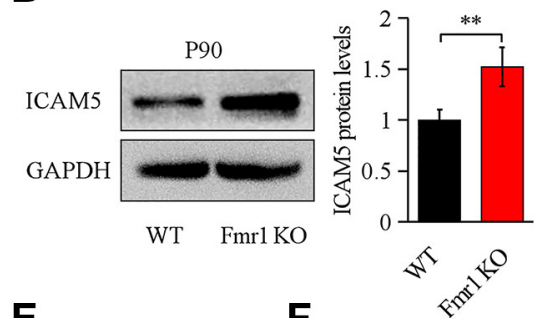

E

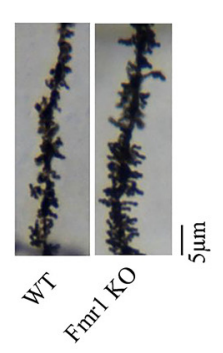

$\mathbf{F}$

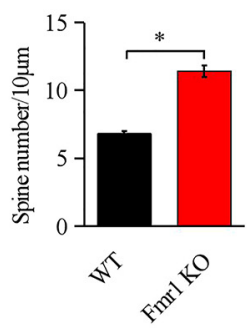

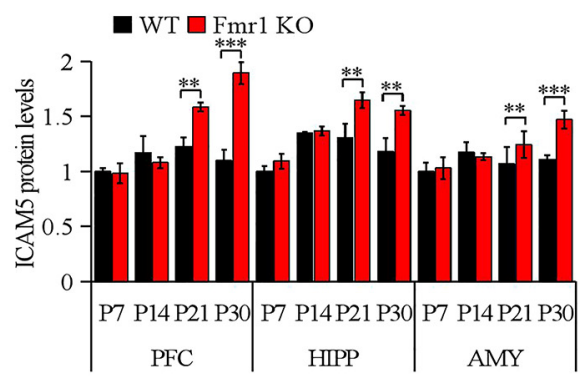

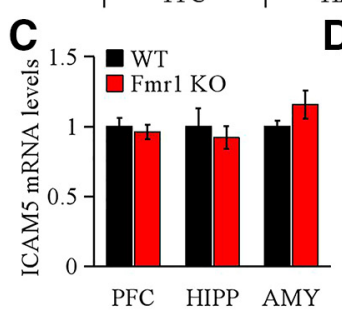

G

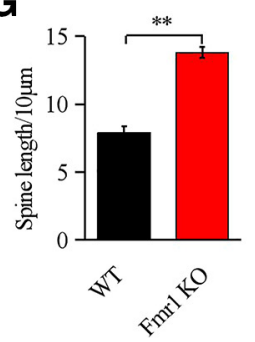

D

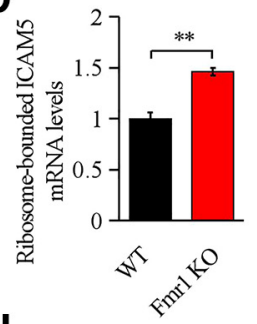

H

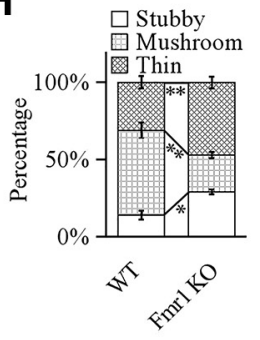

Figure 1. Increased ICAM5 expression and immature spines in Fmr $1 \mathrm{KO}$ mice. $\boldsymbol{A}$, Representative Western blotting images and quantification of ICAM5 expression from three brain regions [the PFC, hippocampus (HIPP), and amygdala (AMY)] during postnatal developmental stage. $\boldsymbol{B}$, Representative Western blotting images and quantification of ICAM5 expression at P90 in the hippocampus. C, Quantification of ICAM5 mRNA with qRT-PCR in prefrontal cortex, hippocampus, and amygdala in Fmr 1 K0 and WT at P21. $\boldsymbol{D}$, Relatively more ribosome-bounded ICAM5 mRNA was found in 21-d-old Fmr1 K0 mice. $\boldsymbol{E}$, Representative photograph of Golgi stained apical dendrites of Fmr $1 \mathrm{KO}$ and WT neurons. $\boldsymbol{F}, \mathbf{G}$, Increased spine number and prolonged spine length in Fmr $1 \mathrm{KO}$ neurons after Golgi staining (per $10 \mu \mathrm{m}$ dendrite). $\boldsymbol{H}$, Dendritic spine classification by morphology in Fmr $1 \mathrm{~K} 0$ and WT hippocampus. $N=$ 480 terminals for WT; and $n=493$ terminals for Fmr 1 KO (6 mice/group). Data are presented as the mean \pm SEM. ${ }^{* *} p<0.001$, ${ }^{* *} p<0.01,{ }^{*} p<0.05$ by unpaired two-tailed Student's $t$ test.

(lysate incubated with anti-FMRP antibody and magnet). Biological replicates were then submitted to Novogene for sequencing. The cDNA library synthesis from total RNA combined with FMRP was performed according to the manufacturer protocols (Illumina). To identify FMRP binding sites on ICAM5 mRNA, we used Crosslinking-Immunprecipitation and HighThroughput sequencing (HITS-CLIP) with MEME and Dreme software (Bailey et al., 2009) to analyze and then Tomtom software (Gupta et al., 2007) to compare the existing motifs in the database.

Stereotactic surgery and virus injection. Mice were anesthetized with isoflurane and placed in a stereotaxic apparatus (item \#68030, RWD). To suppress ICAM5 expression in dentate gyrus (DG), AAV-ICAM5 shRNA-EGFP (BrainVTA) was injected into either DG (coordinates: the anterior-posterior, $-1.70 \mathrm{~mm}$; lateral, $\pm 1.20 \mathrm{~mm}$ ) of 1 -month-old Fmr1 KO mice. Four weeks after virus injection, mice were submitted to the following tests.

Slice physiology. Slices $(400 \mu \mathrm{m})$ were obtained from virus- or vectorinfected Fmr $1 \mathrm{KO}$ male mice. Mice were anesthetized with isoflurane and rapidly decapitated, and brains were quickly removed and transferred into ice-cold artificial CSF (ACSF) containing the following (in mM): 124 $\mathrm{NaCl}, 26 \mathrm{NaHCO}_{3}, 3 \mathrm{KCl}, 2 \mathrm{CaCl}_{2}, 1 \mathrm{MgCl}_{2}, 1.25 \mathrm{KH}_{2} \mathrm{PO}_{4}$, and 10 glucose, pH 7.4 (oxygenated with $95 \% \mathrm{O}_{2}$ and $5 \% \mathrm{CO}_{2}$ ). Slices were cut in ice-cold dissection solution with a vibrating blade microtome and incubated in an interface chamber for $0.5 \mathrm{~h}$ at $34-36^{\circ} \mathrm{C}$ and $1 \mathrm{~h}$ at room temperature. The 64-channel multielectrode (MED64) system (Alpha MED Sciences) was used to record field EPSPs (fEPSPs), as previously described (Chin-Wei et al., 2006; Chang et al., 2015). Slices were placed on the top of the $8 \times 8$ microelectrode arrays (MED-P515A probe), incubated with continuously infused ACSF at $34^{\circ} \mathrm{C}$ at the flow rate of $2 \mathrm{ml} / \mathrm{min}$. Stimuli were delivered to the slice via one selected site, and the intensity was calculated by $50 \%$ of the maximal synaptic response determined by input-output curves, while the response microelectrodes were used to record the fEPSPs. A LTD was induced with low-frequency stimulation ( $1 \mathrm{~Hz}, 900$ pulses).

Spontaneous EPSCs (sEPSCs) were collected from granular cells in the hippocampal DG using conventional whole-cell recording techniques with a Multiclamp 700B amplifier connected to a 1550B analog-to-digital board and Clampex 10 program suite (Molecular Devices). Intracellular solution contained the following (in mM): $150 \mathrm{KCl}, 10 \mathrm{HEPES}, 4 \mathrm{Mg} 2 \mathrm{ATP}$, $0.5 \mathrm{NaGTP}, 10$ phosphocreatine, and $0.2 \%$ biocytin or $135 \mathrm{~K}$-gluconate, $15 \mathrm{KCl}, 5 \mathrm{NaCl}, 0.5$ EGTA, 10 HEPES, 2Mg2ATP, and $0.2 \%$ biocytin, $\mathrm{pH} 7.3$ and $270-290 \mathrm{mOsm}$ and 3-7 $\mathrm{M} \Omega$ resistance. sEPSC were collected in voltageclamp mode at a holding potential value of $-70 \mathrm{mV}$ at a temperature of $30-32^{\circ} \mathrm{C}$. Using the template-based analysis feature of Clampfit 10.0, sEPSC events were collected and analyzed. Access resistance was monitored throughout the experiment, and data from experiments were excluded if the access resistance or the input resistance changed $>20 \%$ during the experiment.

Behavioral tests. Morris water maze (MWM) test and fear-conditioning paradigm test were used to assess spatial learning, fear learning, and memory, as previously described (Zeng et al., 2012). Open field (OF) test and elevated plus maze (EPM) tests were used to characterize the locomotor and anxiety-like behaviors of the mice (Gao et al., 2016).

The social interaction test was performed with a three-chamber device, as previously reported (Tabuchi et al., 2007). After 5 min of habituation, the testing mouse was first placed in the middle chamber, a strange mouse $\mathrm{S} 1$ that had no prior contact with the testing mouse was placed in right-side chamber, while the left-side chamber was empty in session 1 . Then the testing mouse was tested in session 2 with another strange mouse (S2), but in the left chamber, while the right chamber was empty. In session 3 , the testing mouse had options between the first already-investigated $\mathrm{S} 1$ and a new strange mouse (S3). Both doors to the side chambers were then unblocked, and the subject mouse was allowed to explore the entire social test box for $10 \mathrm{~min}$ in each session.

Experimental design and statistical analysis. Fmrl $\mathrm{KO}$ and age-matched WT male mice were used in all experiments. In all cases, four or more animals of the same age and genotype were used for each parameter. Each neuron was considered as an individual data point for dendritic morphological and electrophysiological experiments. For Western blot and behavioral test, $n$ values (number of animals) were reported. Statistical analyses were performed using Microsoft Excel and SPSS 16.0 software. For the comparison between two groups, data were analyzed with an unpaired two-tailed Student's $t$ test. One-way ANOVA and two-way ANOVA followed by Bonferroni's post hoc tests were performed for multiple comparisons. The statistical test and sample size $(n)$ for each experiment were specified in the figure legends. Data were presented as the mean \pm SEM, with $p<0.05$ being considered statistically significant.

\section{Results}

Lack of FMRP in Fmr1 KO mice results in changed ICAM5 expression and immature thin spines

We first examined the expression of ICAM5 expression in the developing prefrontal cortex, hippocampus, and amygdala (Fig. 
1A) in WT and Fmr1 KO mice. In Fmr1 KO mice, ICAM5 expression was increased during late brain development from postnatal day 21 (P21) to P90 when the mice developed a mature hippocampus (Fig. $1 A, B$ ), while in prefrontal cortex and amygdala, the expression of ICAM5 was also found to be increased since P21 (Fig. 1A). At P21, ICAM5 expression in Fmr1 KO mice was increased up to $20 \pm 1.9 \%(p=0.0034)$ relative to that in WT hippocampus, up to $27 \pm 1.5 \%$ in the prefrontal cortex, and $25 \pm$ $1.9 \%$ in the amygdala. However, the ICAM5 mRNA level at P21 was unchanged in the prefrontal cortex, the hippocampus, or the amygdala (Fig. 1C), suggesting a translational disorder of ICAM5 mRNA in Fmr1 KO mice. In accordance with this, polyribosome fractionation analysis showed that ribosome-bounded ICAM5 mRNA was significantly increased $(39 \pm 1.8 \%, p=0.0051)$ in 3 weeks Fmr1 KO hippocampus (Fig. 1D) compared with WT, further suggesting a potential role of FMRP on ICAM5 translation.

As ICAM5 negatively regulates dendritic spine maturation and facilitates immature spine formation (Conant et al., 2011), we examined the dendritic spines of Golgi-impregnated Fmr1 KO and WT neurons. As shown in Figure 1, F and $G$, spine number and length measurements were significant higher in $\mathrm{KO}$ neurons compared with those in WT hippocampus neurons at P21 $(40 \pm 2.8 \%, p=$ $0.039 ; 43 \pm 1.7 \%, p=0.0032$ ). The same tendency was also found in the prefrontal cortex and the amygdala (data not shown), indicating a spine overproduction in FXS. Concomitantly, during P21 and the later brain development, WT spines exhibited a steady state, whereas Fmr1 KO spines remained at prepruning levels. As shown in Figure $1 H$, at $\mathrm{P} 21$, the percentages of immature thin and stubby spines in the Fmr1 KO hippocampus were significantly higher than that in WT hippocampus $(26 \pm 3.1 \%, p=0.0071)$, while mature mushroom-shaped spines were significantly decreased ( $34 \pm 2.7 \%, p=0.0051)$. These results showed a developmental delay in the downregulation of spine turnover and in the transition from immature to mature spine subtypes, which matches the time course and reported role of ICAM5 overexpression in the literature (Raemaekers et al., 2012).

\section{Reduction of ICAM5 normalizes dendritic spine abnormalities in Fmr1 KO neurons}

To verify the involvement of ICAM5 in dendritic spines, we suppressed ICAM5 expression in Fmr1 KO neurons and compared with neurons transfected empty lentiviral vectors (Mock). As shown in Figure 2, $A$ and $B$, ICAM5 protein level in Fmr1 KO neurons was significantly decreased by ICAM5 shRNA (45 \pm $1.6 \%, p=0.0114$ ), validating ICAM5 protein suppression. The total spine number was not modified by ICAM5 suppression (Fig. 2C,D). However, the thin spines in ICAM5 shRNA Fmr1 KO neurons were fewer than those in controls $(39 \pm 2.4 \%, p=$ 0.0143; Fig. $2 C, F)$, and no significant changes in stubby spines, while the mushroom spines increased $(23 \pm 2.6 \%, p=0.0289)$, which suggests that ICAM5 suppression attenuated the aberrant maturation of dendritic spines in Fmr1 KO neurons. In addition, the mean length of all spine types was significantly decreased $(18 \pm 1.8 \%, p=0.0153$; Fig. $2 E)$. Together, these data demonstrate that the overexpression of ICAM5 in FXS is positively related to the abnormal dendritic spine length and maturation in Fmr1 KO neurons.

FMRP affects ICAM5 protein expression and dendritic morphology in cultured neurons

To identify whether the increased ICAM5 protein level in Fmr1 KO mice resulted from the loss of FMRP, we modified the FMRP protein levels in WT and KO neurons and examined the altera-
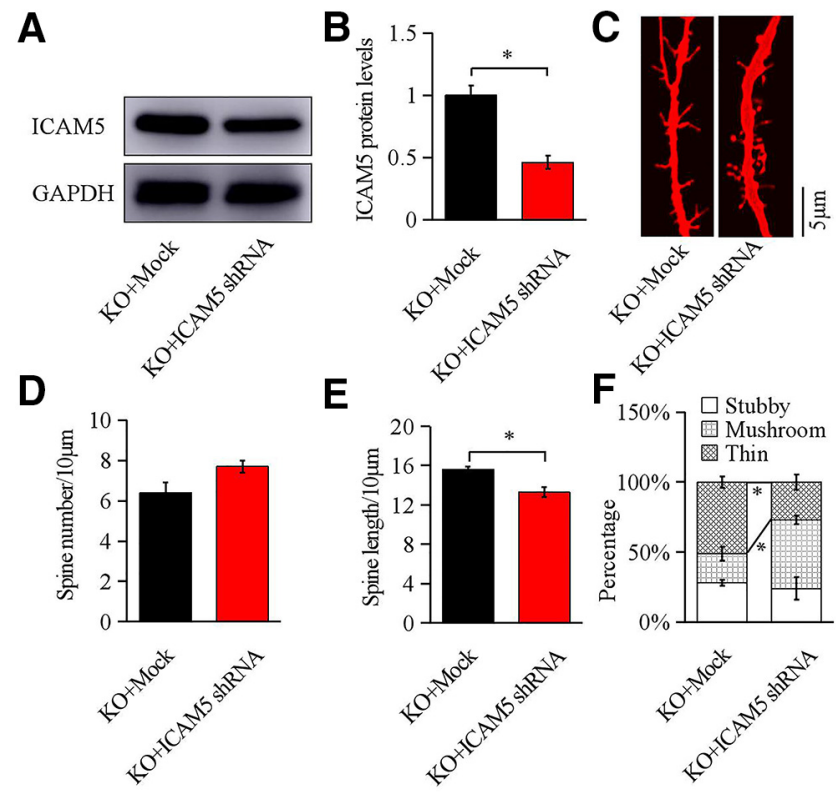

Figure 2. ICAM5 shRNA affected dendritic morphology in cultured Fmr $1 \mathrm{KO}$ neurons. $\boldsymbol{A}, \boldsymbol{B}$ Representative Western blotting images of ICAM5 and quantification of ICAM5 expression after transfection. C, Representative dendritic segments from Fmr $1 \mathrm{KO}$ neurons after transfection (Dil staining). $\boldsymbol{D}, \boldsymbol{E}$, Statistical analyses of the number and length of spines per $10 \mu \mathrm{m}$ dendrites. $\boldsymbol{F}$, Morphology analyses for thin, mushroom, and stubby-shaped spines. $N=506$ terminals for $\mathrm{KO}+$ Mock and $n=500$ terminals for KO + ICAM5 shRNA (8 mice/group). Data are presented as the mean \pm SEM. ${ }^{*} p<0.05$ by unpaired two-tailed Student's $t$ test.

tions in ICAM5 expression and dendritic morphology. Two days after transfection with lentiviral vector, FMRP and ICAM5 expression was tested by Western blotting. As shown in Figure 3, the ICAM5 protein level was negatively correlated with the FMRP level. In WT neurons, ICAM5 was significantly increased (30 \pm $1.5 \%, p=0.0342$; Fig. $3 A, B)$ by FMR1 interference, and ICAM5 mRNA was kept unchanged (Fig. $3 C ; p=0.0924$ ); whereas FMR1 overexpression significantly decreased ICAM5 in KO neurons $(35 \% \pm 1.2 \%, p=0.0272$; Fig. $3 I, J)$, without affecting ICAM5 mRNA (Fig. $3 K ; p=0.0853$ ). However, polyribosome fractionation analysis showed that ribosome-bounded ICAM5 mRNA was significantly increased $(23 \pm 1.3 \%, p=0.0283)$ after FMR1 interference in WT neurons (Fig. 3D), and the consistently FMR1 overexpression resulted in reduced ribosome-bounded ICAM5 mRNA in KO neurons $(32 \pm 2.0 \%, p=0.0121$; Fig. $3 L)$, indicating the role of FMRP on ICAM5 translation.

To further examine the translational effect of FMR1 on dendritic morphology, we observed spine morphology $7 \mathrm{~d}$ after FMR1 shRNA or Ovp-FMR1 lentiviral transfection. Spine length was significantly elongated in FMR1 knock-down WT neurons $(28 \pm 2.9 \%, p=0.0204$; Fig. $3 E, G)$ and shortened in FMR1 overexpression KO neurons $(18 \pm 3.1 \%, p=0.0294$; Fig. $3 M, O)$. Furthermore, the percentage of thin spines in FMR1 knock-down WT neurons increased by $47 \pm 2.7 \%(p=0.0113)$ over that in controls (Fig. $3 H$ ), while the percentage of mushroom spines was significantly reduced $(44 \pm 3.3 \%, p=0.0192)$. By contrast, the percentage of thin spines decreased in FMR1-overexpressed KO neurons $(33 \% \pm 2.8 \%, p=0.0221$, Fig. $3 M, P)$ and the mushroom spines increased $(29 \pm 3.3 \%, p=0.0382)$. These results indicate that FMRP-related ICAM5 protein expression corresponds with dendritic spine morphology, although the total number of dendritic spines was not changed (Fig. $3 F, N$ ). Given 


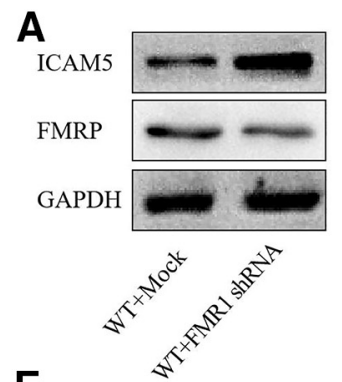

E
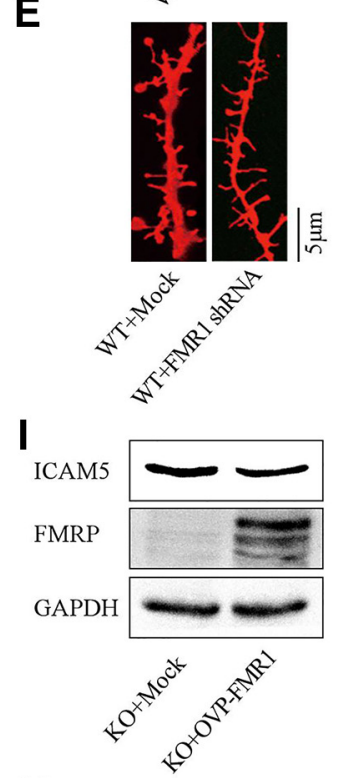

M

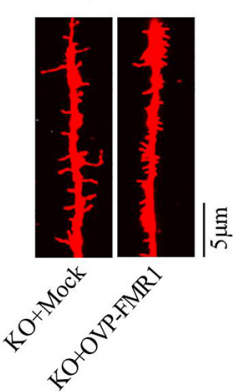

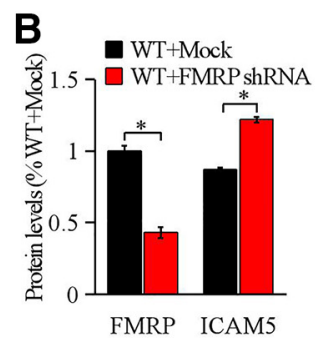

F
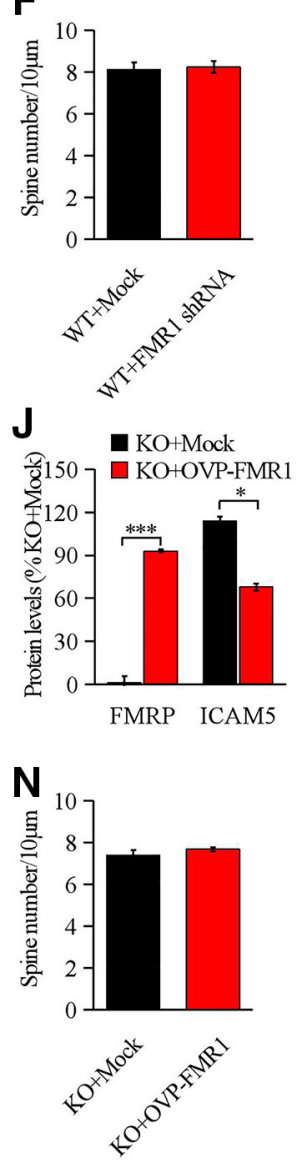

C

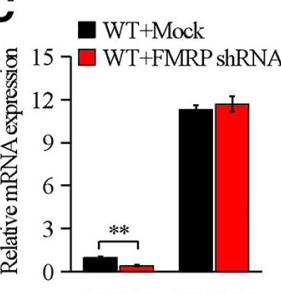

FMRP ICAM5

G
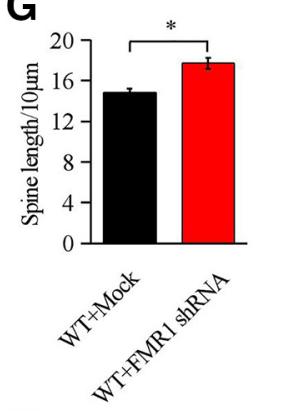

K $\quad$ KO+Mock

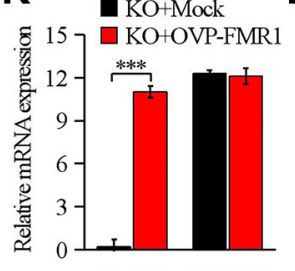

FMRP ICAM5
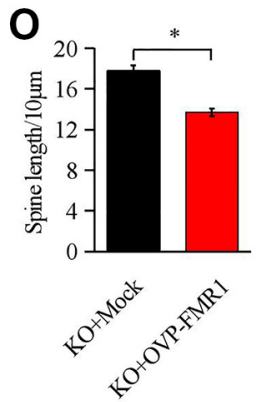
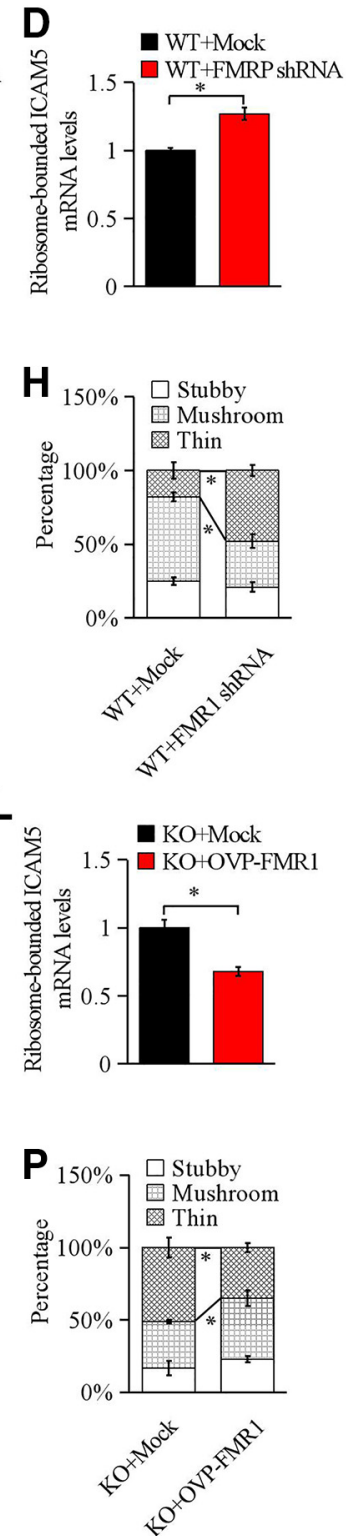

Figure 3. FMR1 affected ICAM5 protein expression and dendritic morphology in cultured WT and KO neurons. $\boldsymbol{A}-\boldsymbol{H}$, FMR1 shRNA transfected cultured WT neurons. $\boldsymbol{A}, \boldsymbol{B}$, Raised ICAM5 and reduced FMRP expression after FMR1 shRNA transfection. $\boldsymbol{C}, \boldsymbol{D}, \mathrm{qRT}$-PCR analyses of total and ribosome-bounded ICAM5 mRNA, respectively. $\boldsymbol{E}-\boldsymbol{G}$, Representative dendritic segments from cultured neurons $(\boldsymbol{E}$; Dil staining) and statistical analyses of spine number/length $(\boldsymbol{F}, \boldsymbol{G})$ per $10 \mu \mathrm{m}$ dendrites. $\boldsymbol{H}$, Dendritic spine classification by morphology after FMR1 interference. $N=496$ terminals for WT + Mock, $n=470$ terminals for WT+ FMR1 shRNA (8 mice/group). I-P, FMR1 overexpression transfected cultured K0 neurons. I, J, Representative Western blotting images and quantification of ICAM5 and FMRP. $\boldsymbol{K}, \mathbf{L}$, qRT-PCR analyses of total and ribosome-binding ICAM5 mRNA, respectively. $\boldsymbol{M}-\mathbf{0}$, Representative dendritic segments from cultured neurons (Dil staining) and statistical analyses of spine number/length per $10 \mu \mathrm{m}$ dendrite. $\boldsymbol{P}$, Dendritic spine classification by morphology after FMR1 overexpression. $N=490$ terminals for K0 + Mock, and $n=524$ terminals for KO + OVP-FMR1 (8 mice/group). Data are presented as the mean \pm SEM. ${ }^{* * *} p<0.001,{ }^{* *} p<0.01,{ }^{*} p<0.05$ by unpaired two-tailed Student's $t$ test.

the role of ICAM5 in dendritic spine formation and maturation, as reported in the literature (Raemaekers et al., 2012) and confirmed in this study (Fig. 2), we hypothesize that FMRP directly affects ICAM5 expression, which consequently influences spine morphology.

\section{FMRP directly binds to ICAM5 mRNA in vitro}

To determine whether ICAM5 mRNA is an FMRP target, we tested the FMRP-ICAM5 mRNA interaction in vitro with RIP followed by qRT-PCR and DNA gel electrophoresis. As shown in Figure $4 A$ and $B$, ICAM5 mRNA appeared in the FMRP antibodyextracted group and the total input group, but not in the IgG extracted or Blank (no template PCR control) groups, indicating a direct binding of FMRP to ICAM5.
HITS-CLIP results show that 10 FMRP-connected mRNA motifs were frequently detected, and 6 of them were highly matched with the ICAM5 mRNA sequence (Fig. 4C,D). Namely, they were AGACMMM, RAAAAWC, ARAAAAW, CACAGCA, SCVAVCH, and TSKGGKC $(\mathrm{M}=\mathrm{A} / \mathrm{C}, R=\mathrm{A} / \mathrm{G}, \mathrm{W}=\mathrm{A} / \mathrm{T}, \mathrm{K}=\mathrm{G} / \mathrm{U}, \mathrm{S}=\mathrm{G} / \mathrm{C}$, $\mathrm{V}=\mathrm{G} / \mathrm{A} / \mathrm{C}$, and $\mathrm{H}=\mathrm{A} / \mathrm{T} / \mathrm{C})$. Within the ICAM5 mRNA, $93 \%$ of the six motifs appeared within the coding sequence (CDS; Fig. 4D). Most of them are located very close to one another, and some are overlapped (data not shown). Gene Ontology (GO; http:// www.geneontology.org/) was used to gain insight into the biological functions encoded by the FMRP target transcripts. As seen in Figure $4 E$, the FMRP target transcripts were mainly located around the nucleus- and membrane-bounded organelles, suggesting the direct biological modulating role of FMRP on ICAM5. 
A

C

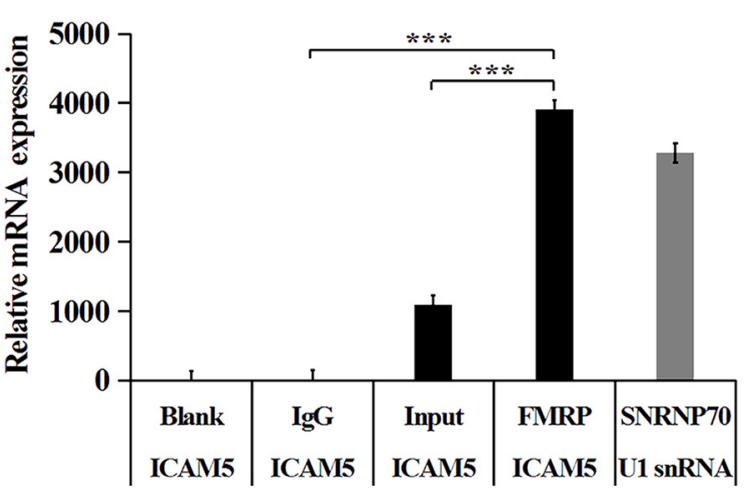

B

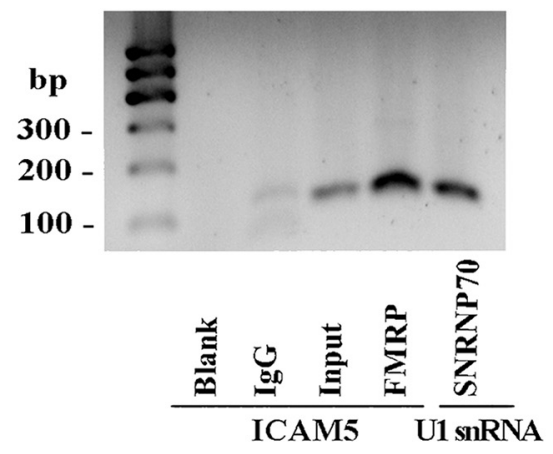

$\mathbf{a}_{2}$

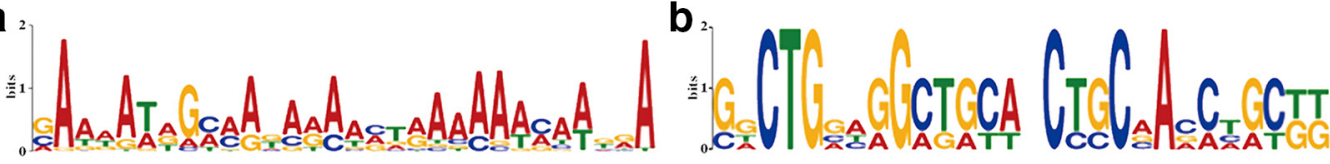

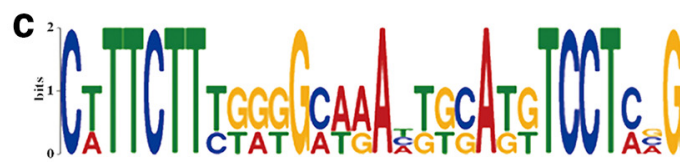

e

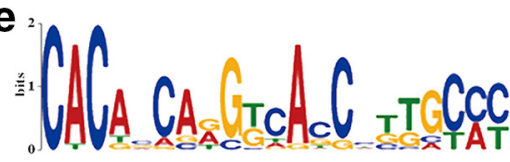

D

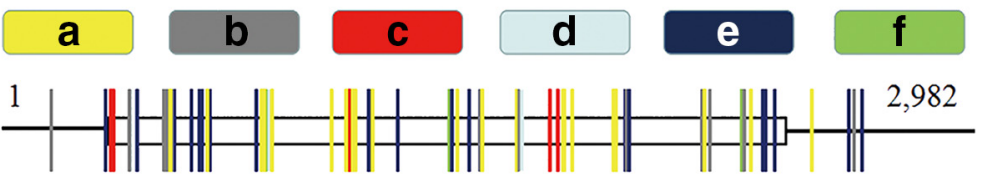

ICAM5, RPKM=6.32.

f d

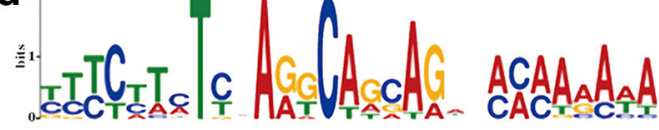

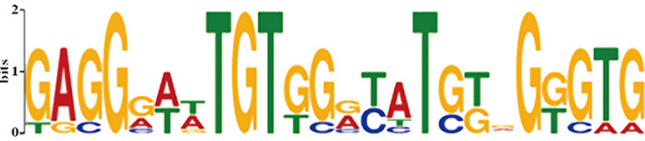

- 5'UTR and upstream $10 \mathrm{~K}$

- 3'UTR and downstream 10K

cDS

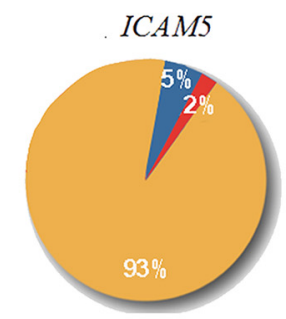

E

The Most Enriched GO Terms

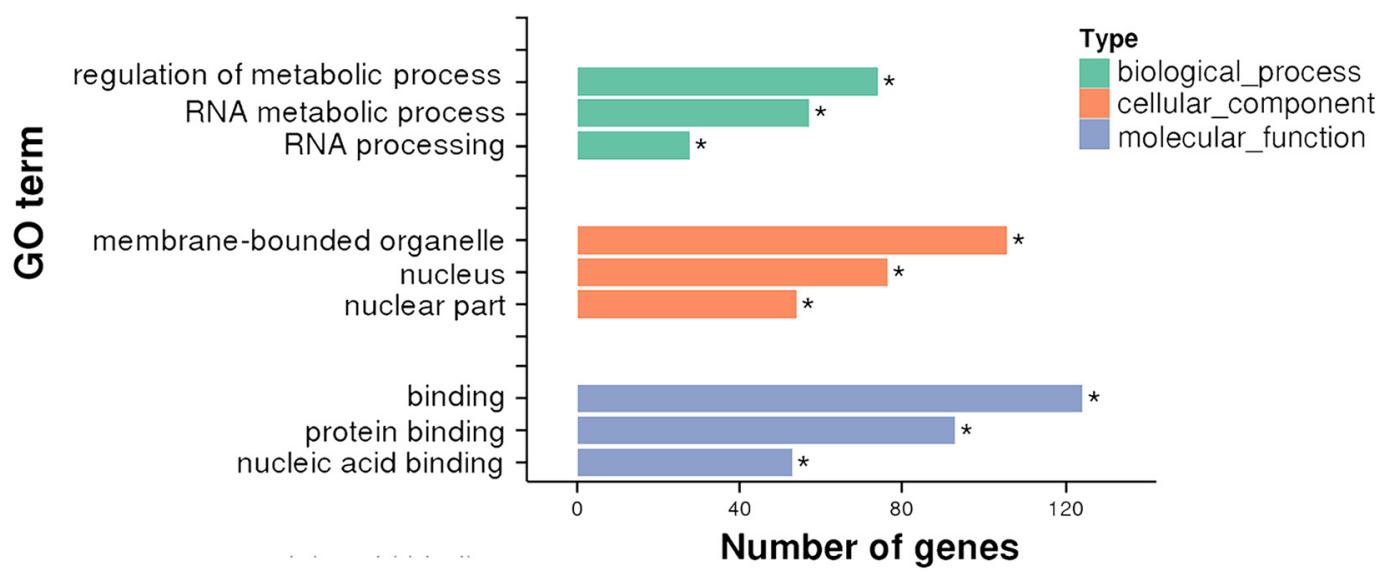

Figure 4. FMRP binding sites on ICAM5 mRNA determined by sequence analysis. A, ICAM5 mRNA was found in the FMRP-extracted group by qPCR. Negative control: Blank and IgG groups. Positive control: ICAM5 $\mathrm{mRNA}$ in lysate input group and U1 snRNA in SNRNP70 group. ${ }^{* * *} p<0.001$ by one-way ANOVA with a Bonferroni's post hoc test. $B$, DNA gel electrophoresis of the qPCR products of A. $\boldsymbol{C}$, Six major ICAM5 RNA recommended segments $(\boldsymbol{a}-\boldsymbol{f})$ that were inferred to be the FMRP binding sites. $\boldsymbol{D}$, Left, Distribution of the six FMRP binding motifs ( $\boldsymbol{a}-\boldsymbol{f}$ ) across the representative ICAM5 mRNA. Open boxes and bold lines indicate CDS and untranslated regions (UTRs), respectively. Right, Occurrence frequency of the six motifs in CDS and UTRs. $E$, The top three G0 terms enriched in FMRP target transcripts and their $\mathrm{G} 0$ categories; $n=3 .{ }^{*} p_{\text {adj }}<0.05$ (Benjamini-Hochberg). 
A

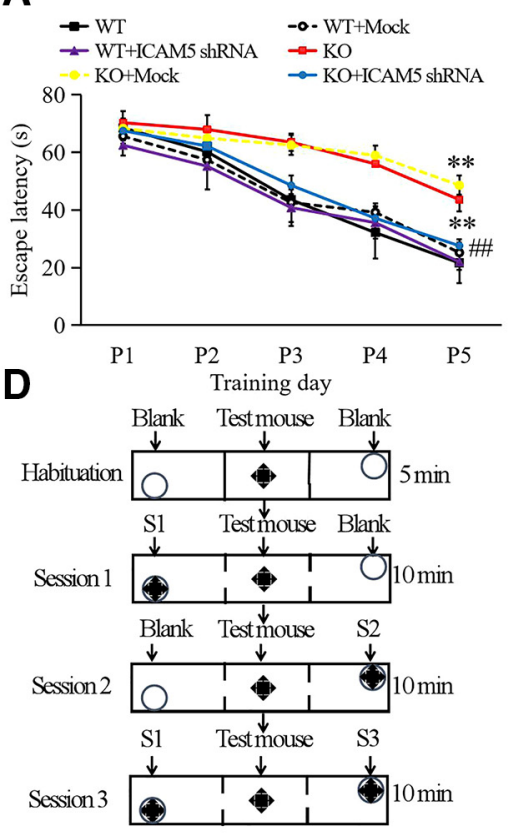

G

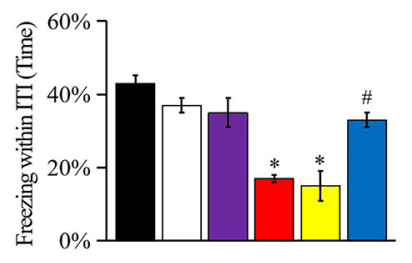

B

- WT ○ WT+Mock «WT+ICAM5 shRNA

KO KO+Mock - KO+ICAM5 shRNA

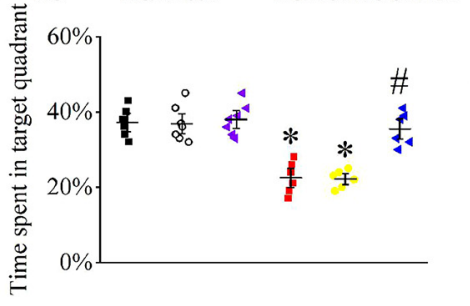

E

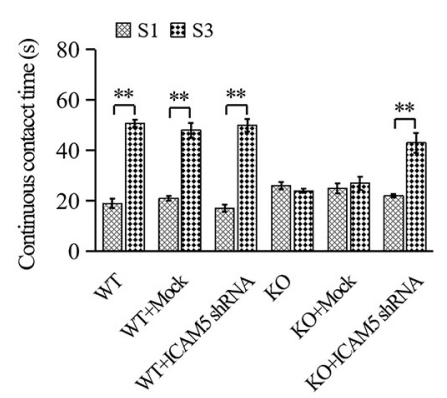

H

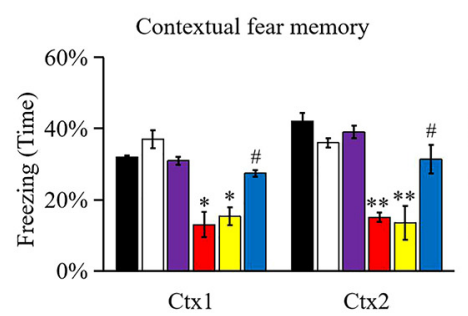

C

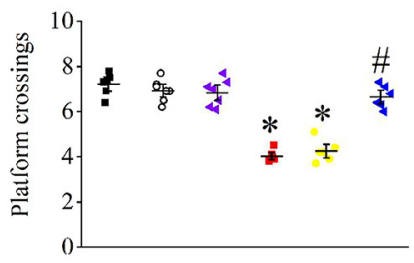

\section{F}
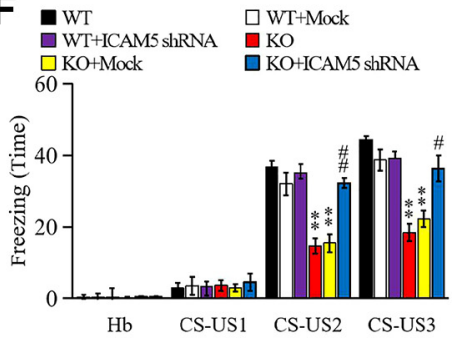

I

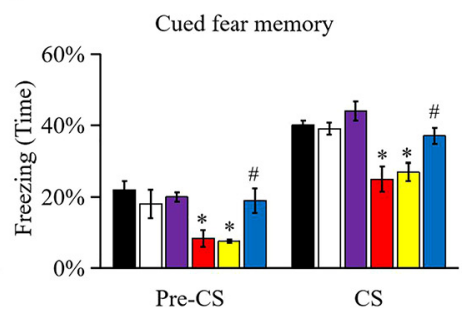

Figure 5. ICAM5 knockdown rescued the impaired behavioral performances in Fmr $1 \mathrm{KO}$ mice. $A-C$, MWM test. $A$, Mean escape latency of reaching the submerged platform during the training period. $\boldsymbol{B}, \boldsymbol{C}$, Time spent in target quadrant and platform crossings after training. $\boldsymbol{D}, \boldsymbol{E}$, Social interaction test. $\boldsymbol{D}$, The scheme of the three-chamber social interaction test. $\boldsymbol{E}$, Contact time of the testing mouse with a strange mouse. $\boldsymbol{F}$ - $\boldsymbol{I}$, Fear-conditioning paradigm test. $\boldsymbol{F}$, Percentage of freezing during the period of associative conditioned stimulus-unconditioned stimulus (CS-US) pairing. $\boldsymbol{G}$, Averaged freezing time during the intertrial intervals (ITIs) of the testing session. $\boldsymbol{H}, \boldsymbol{I}$, Contextual fear conditioning and cued fear conditioning $24 \mathrm{~h}$ after CS-US pairing stimulation. $N=6$ for WT, $n=7$ for WT + Mock, $n=7$ for WT + ICAM5 shRNA, $n=6$ for KO, $n=6$ for KO + Mock, and $n=6$ for KO + ICAM5 shRNA. Data are presented as the mean \pm SEM. Two-way ANOVA was used with a Bonferroni's post hoc test for statistical analysis. ${ }^{*} p<0.01,{ }^{*} p<0.05$ compared with WT; \#\#p $<0.01$, \#p $<0.05$ compared with Fmr 1 K0 mice.

\section{Genetic reduction of ICAM5 in DG corrects behavioral deficits in FXS}

To evaluate the functional relevance of elevated ICAM5 expression in FXS, we examined spatial and fear memory and exploratory and anxiety-like behaviors in Fmr1 KO and ICAM5 knock-down (AAVICAM5 shRNA-EGFP) Fmr1 KO mice, and compared their performance with WT, ICAM5 knock-down WT, and adenovirus empty vector (AAV-EGFP)-transfected Fmr1 KO and WT mice.

We first evaluated spatial memory with the hidden platform MWM. During the training sessions, KO mice showed significantly longer escape latencies than WT mice, but the latency was shortened in ICAM 5 shRNA KO mice (Fig. 5A). After $5 \mathrm{~d}$ of training, spatial memory retention was evaluated by removing the hidden platform. KO mice $(39 \pm 2.3 \%, p=0.0255$, vs WT mice) showed no preference for the correct quadrant, whereas both the WT and ICAM5 shRNA KO groups spent more time in the correct quadrant (Fig. 5B) and crossed the previous hidden platform location more frequently (Fig. $5 C$ ), which suggested the impairment of spatial memory performance of Fmr $1 \mathrm{KO}$ mice and correction by the reduction of ICAM5 expression. WT mock and ICAM5 shRNA WT mice exhibited no difference from WT. In addition, at the visible-platform test, all groups of mice showed comparable escape latency and swimming speed (data not shown), sug- gesting a comparable motor and visual function among the different mice, and no change in vision or swimming speed was found that could influence the behavioral tests.

The social interaction test was performed as shown in the schematic drawing (Fig. 5D). After habituation, all mice presented a preference for strange mouse, $\mathrm{S} 1$ in session 1 and for S2 in session 2, over Blank (data not shown). However, in session 3, WT and ICAM5 shRNA KO mice showed a preference for new strange mouse $\mathrm{S} 3$, instead of re-put mouse $\mathrm{S} 1$ (Fig. $5 E ; 54 \pm 2.9 \%$, $p=0.0130 ; 50 \pm 2.0 \%, p=0.0183)$. However, $\mathrm{KO}$ and $\mathrm{KO}$ Mock groups did not show the preference $(p=0.6364$ and $p=0.4272)$, indicating reduced social interaction and memory in Fmrl KO mice and reversed the effect of ICAM 5 reduction. WT mock and ICAM5 shRNA WT mice showed no difference from WT.

For the fear-conditioning learning test, during the second and third tone-shock pairs (Fig. $5 F$ ), freezing time was decreased $\sim 50 \pm 3.5 \%(p=0.0065)$ in $\mathrm{KO}$ mice relative to WT mice. During the intermission, $\mathrm{KO}$ mice also showed less freezing time, suggesting impaired fear memory (Fig. $5 G ; p=0.0124$ ). A day after the contextual test, $\mathrm{KO}$ mice continued to exhibit less freezing time (Fig. $5 H ; p=0.0219$ ) when delivered into the contextual fear-conditioning environment. There was also decreased memory consolidation for cued fear conditioning (Fig. 5I; $p=0.0153$ ) 
A

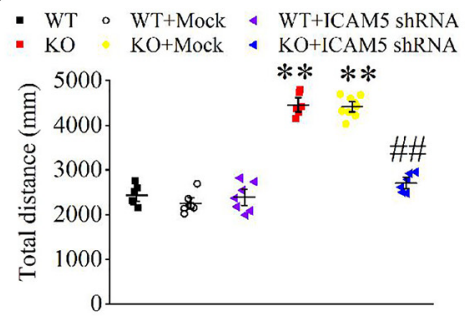

D

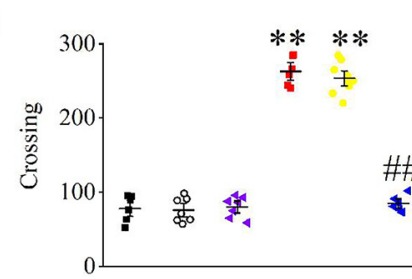

B

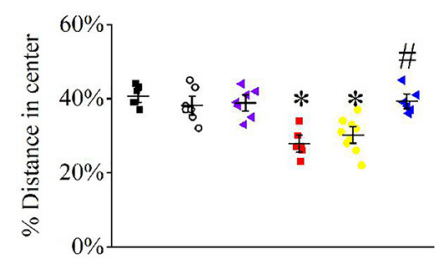

E

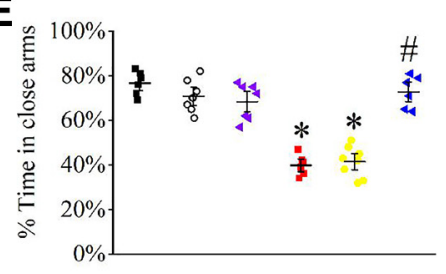

C

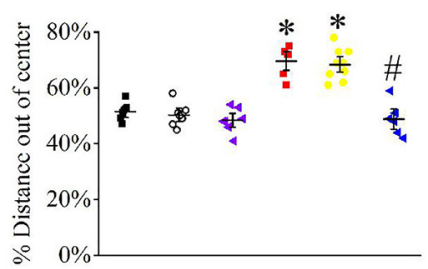

F

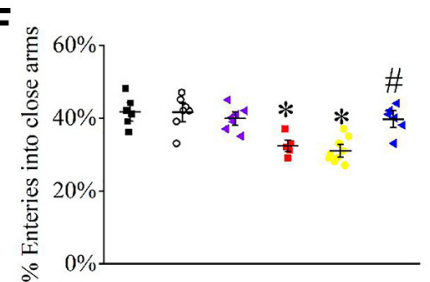

G

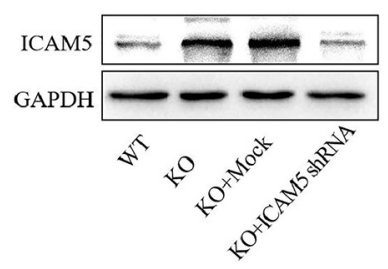

J

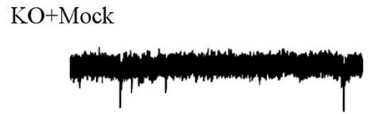

KO+ICAM5 shRNA

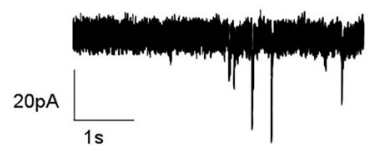

H - wT

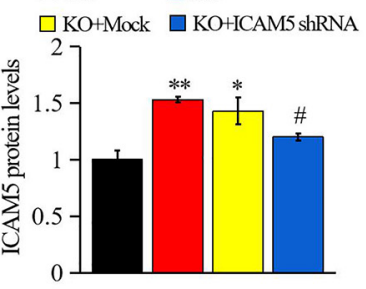

\section{I}
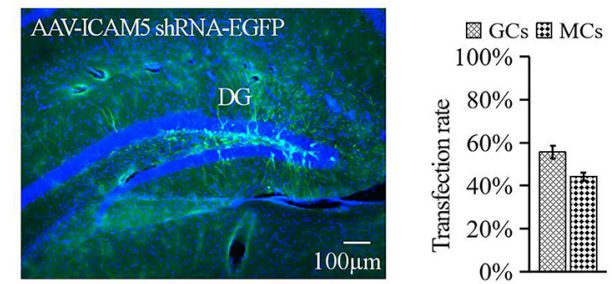

L

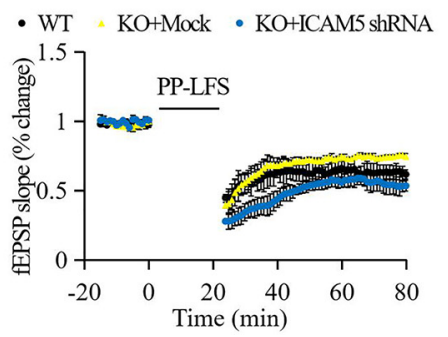

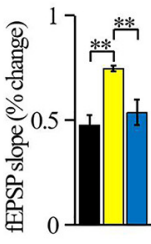

Figure 6. ICAM5 knockdown improved the locomotor or anxiety-like behaviors in $F m r 1 \mathrm{KO}$ mice. $\boldsymbol{A}-\boldsymbol{D}, 0$ pen-field test. $\boldsymbol{A}$, Overall distance traveled during the 5 min open-field test. $\boldsymbol{B}, \boldsymbol{C}$, Percentages of the distance in the center area over total distance $(\boldsymbol{B})$ and peripheral distance over total distance $(\boldsymbol{C})$. D, Number of times across the cells per minute. $\boldsymbol{E}, \boldsymbol{F}$, Elevated plus maze. $\boldsymbol{E}$, Times entered into closed arms over total entries into both closed and open arms. $F$, Percentage of time spent in closed arms. $N=6$ for WT, $n=7$ for WT + Mock, $n=7$ for WT + ICAM5 shRNA, $n=$ 6 for K0, $n=9$ for KO + Mock, and $n=6$ for KO + ICAM5 shRNA. ${ }^{* *} p<0.01,{ }^{*} p<0.05$ compared with WT; \#\#p $<0.01$, \#p $<0.05$ compared with Fmr 1 K0 mice. G, $\boldsymbol{H}$, ICAM5 expression in hippocampus after ICAM5 knockdown. I, Confocal images (left) of the KO dentate gyrus transfected with ICAM5 shRNA virus (green) and DAPI staining nucleus (blue), while the percentages of transfected GCs and MCs are shown on the right. $N=7 . J, K$, Example and statistical analyses of sEPSC amplitude and frequency in EGFP expressed neurons in KO mock and K0 ICAM5 shRNA mice. $N=18$ neurons for $K 0+$ Mock and $n=14$ neurons for KO + ICAM5 shRNA (4 mice/group). L, Representative traces before and after LTD induction (left) and mean fEPSP slopes averaged $50-60$ min after LTD induction (right). $N=7$ for WT, $n=6$ for KO + Mock, and $n=5$ for KO + ICAM5 shRNA. Data are presented as the mean \pm SEM; unpaired two-tailed Student's $t$ test and two-way ANOVA with a Bonferroni's post hoc test were used for statistical analysis. ${ }^{* *} p<0.01,{ }^{*} p<0.05$.

$2 \mathrm{~h}$ after the contextual fear-conditioning test. All above impaired memory-related behaviors were improved in ICAM5 shRNA KO mice compared with $\mathrm{KO}$ mice, during the contextual test (Fig. $5 G ; p=0.0166$ ), in the conditioning environment (Fig. $5 H ; p=$ 0.0138 ), and cued fear condition (Fig. 5I; $p=0.0247$ ), whereas WT mock and ICAM5 shRNA WT mice had no difference compared with WT mice.

In addition, the mice were then tested for exploratory behavior in the OF test (Fig. 6A-D). Fmrl KO mice exhibited longer total travel distance (Fig. $6 A ; 46 \pm 2.3 \%, p=0.0053$ ); however, a lower percentage of total distance inside the center than with WT mice (Fig. $6 B ; 39 \pm 2.8 \%, p=0.0211$ ), and a greater percentage of the total distance out of center (Fig. $6 C ; 21 \%, p=0.0283$ ), and a greater number of times across the edges (Fig. $6 D ; 58 \pm 1.9 \%, p=$ $0.0315)$. The results suggested a significantly elevated exploration activity and unconditioned anxiety-related behavior in Fmr1 KO mice, which was reversed by DG ICAM5 knockdown for total travel distance (Fig. $6 A ; 38 \pm 3.6 \%, p=0.0032$ ), center distance (Fig. $6 B ; 24 \pm 2.1 \%, p=0.0455$ ), out-of-center distance (Fig. $6 C$; $21 \%, p=0.0365$ ), and times across the edges (Fig. $6 D ; 57 \pm 4.4 \%$, $p=0.0024)$. In the EPM test, Fmrl KO mice also showed impaired anxiety-like behavior. Fmr1 KO mice displayed less time spent in and fewer times entering the closed arms (Fig. 6E,F; $35 \pm 3.7 \%, p=0.0145$; and $18 \pm 2.4 \%, p=0.0426$ ), which was also recovered in the ICAM5 shRNA group $(28 \pm 1.6 \%, p=$ 0.0211 and $16 \pm 1.5 \%, p=0.0421)$. Instead, WT mock and ICAM5 shRNA WT mice showed no difference from WT mice in the OF and EPM test.

After the behavioral tests, mice were killed, and their brains were collected for detecting transfection efficiency and ICAM5 expression. The ICAM5 protein level in the Fmr1 KO hippocampus was significantly decreased by ICAM5 shRNA intervention 
(43 $\pm 1.1 \%$; Fig. $6 G, H)$. Moreover, the large amount of EGFP expression showed that AAV-ICAM5 shRNA-EGFP was successfully transfected into the dentate gyrus (Fig. 6I), validating ICAM5 protein suppression. Surprisingly, both granule cells (GCs) and mossy cells (MCs) were transfected with a relative rate of $1.32 \pm$ 0.15 , accounting for $56.94 \pm 2.96 \%$ and $43.06 \pm 2.32 \%$ of total transfected cells.

To investigate the electrophysiological modification after ICAM5 suppression, sEPSC was recorded on the EGFP-expressed neurons after Mock or ICAM5 shRNA injection. Compared with the Mock group, ICAM5 shRNA intervention significantly increased the amplitude of sEPSCs (Fig. $6 J, K ; p=0.0160$ ) without changing the frequency (Fig. $6 \mathrm{~J}, K$ ) in GCs, which was consistent with the results of morphological maturation of the dendritic spines (Fig. $2 F$ ). Besides, ICAM5 shRNA intervention significantly rescued the impaired synaptic plasticity, where the classic abnormal LTD is improved (Fig. $6 L ; p=0.0032$ ). Although, we did not observe significant difference in LTP between Fmr1 KO and WT mice (data not shown), which is also found by many groups based on different experimental conditions (Li et al., 2002; Larson et al., 2005).

\section{Discussion}

The present study verified for the first time the novel FMRP target ICAM5 mRNA and explored its contribution to spine abnormalities and behavioral defects in FXS. We found that the loss of FMRP relieves its direct binding with ICAM5 mRNA and induces ICAM5 overexpression, which is translationally related to dendritic spine morphological abnormalities in Fmr1 KO neurons. Viral intervention of ICAM5 expression in DG reverses the cognitive deficits in the FXS mouse model Fmr1 KO mice, demonstrating the therapeutic value of ICAM5 for treating cognitive dysfunctions in FXS. To our knowledge, this is the first study that detected the role of ICAM5 in cognitive function in vivo.

A salient neuropathological defect in FXS is dendritic spine dysgenesis, but its underlying mechanism is still unclear. Previous reports indicate that FMRP regulates the expression of synaptic proteins including PSD-95, CaMKII $\alpha$, and MAP1B (Lu et al., 2004; Hou et al., 2006; Zalfa et al., 2007; Kao et al., 2010; Darnell, 2010; McMahon and Rosbash, 2016). ICAM5 is also reported to promote spine outgrowth via homophilic binding (Tian et al., 2000; Recacha et al., 2014), via ICAM5-ERM (ezrin/ radixin/moesin) interaction and ectodomain interaction with $\beta 1$ integrins (Yang, 2012). The homophilic adhesion of ICAM5 mediates the induction of dendritic outgrowth (Tian et al., 2000), since the ICAM5 cytoplasmic region binds ERM family proteins that link membrane proteins to actin cytoskeleton (Furutani et al., 2007), while the ICAM5 and $\beta 1$ interaction via the two first Ig domains stimulates cofilin phosphorylation and facilitates matrix metalloproteinase-dependent spine maturation (Conant et al., 2011; Ning et al., 2013). However, ICAM5, the direct negative regulator of dendritic spine maturation has never been examined in FXS. ICAM5 is expressed at low levels in embryos but rapidly increased after birth when large numbers of synapses are formed (Matsuno et al., 2006). During spine maturation, ICAM5 expression gradually decreases (Matsuno et al., 2006), which is also observed in our results with age. However, in Fmr1 KO mice, since postnatal day 21 , ICAM5 was more abundantly expressed than in WT mice, which is consistent with the timing of increased thin spines and decreased mushroom spines. Besides, reduced ICAM5 expression resulted in spine maturation (Fig. $2 F$ ) and synaptic response (Fig. 6J-L) in Fmr1 KO neurons, indicating the involvement of ICAM5 in KO neuron spine formation. Regarding the reported effect of ICAM5 in spine pruning and formation (Matsuno et al., 2006), these results indicated a critical role of ICAM5 in FXS spine maturation and brain development. Considering that ICAM5 increases after P21, the alterations in spine length and numbers at P14 indicate the existence of multiple mechanisms in FXS spine abnormality.

FMRP is an RNA-binding protein controlling mRNA translation by promoting its dynamic transport and stalling its translation (Darnell et al., 2011; Darnell and Klann, 2013). Most of the previous studies supported that FMRP binds to a large number of mRNAs (Darnell et al., 2011). Our results showed that ICAM5 expression is excessively expressed in Fmr1 KO mice, and the expression of FMRP was negatively correlated with the expression of ICAM5. Further experiment indicated that FMRP interacts directly with ICAM5 mRNA, which is consistent with the findings of Darnell et al. (2011). In addition, FMRP bound ICAM5 mRNA predominantly in the coding regions and mainly located around the nucleus and membrane-bound organelles. FMRP is well known for binding proteins and RNA, in turn regulating RNA processing and metabolism (Zhang et al., 2015), which corresponds with the biological modulation of FMRP on ICAM5 mRNA in our study. These results indicate the overexpressed ICAM5 attributed to the loss of FMRP in FXS.

Since both ICAM5 (Mizuno et al., 1997) and FMRP (Hinds et al., 1993) are highly expressed in the cortex and amygdala in WT mice, in addition to hippocampus we also detected ICAM5 expression in the cortex and amygdala in FXS. The results are consistent in all three regions that ICAM5 was excessively expressed in Fmr1 KO mice, indicating that loss of FMRP-induced ICAM5 overexpression could lead to a potential broad pathological consequence in the mammalian brain and FXS. Indeed, we found remarkable numbers of immature spines in neurons from these three regions. The overexpressed ICAM5 corresponded to the timing of increased thin spines and decreased mushroom spines. All of these results indicate a potential broad role of ICAM 5 in the mammalian brain and FXS.

The role of ICAM5 has been well studied for the last decade; however, the therapeutic role of ICAM5 is still unclear (e.g., whether abnormal ICAM5 expression could influence any behavioral disorders in vivo is never studied). Our results indicated that ICAM5 knockdown reversed behavioral disorders in Fmr1 KO mice. Intellectual disability is a characteristic phenotypic feature of FXS, which is not fully understood and cannot be improved by current medication. As reported by many research groups, Fmr1 KO mice exhibited impaired memory and exploratory and anxietylike behaviors (Spencer et al., 2005; Baker et al., 2010), which were ameliorated to some degree by lowering ICAM5 expression in DG, a pivotal area connecting amygdala and prefrontal cortex (Zancada-Menendez et al., 2017). Interestingly, ICAM5 suppression did not change the behavior in WT mice. It has been reported that ICAM5-deficient mice showed a decreased density of filopodia and an acceleration of spine maturation in vitro and in vivo (Matsuno et al., 2006). However, it is unclear whether ICAM5-deficient mice exhibit behavior change, and it could be interesting for future study to evaluate the effect of ICAM5 suppression in normal WT mice. Thus, the overexpression of ICAM5 in postnatal development in Fmr1 KO mice may be a neurobiological mechanism for FXS pathological phenotypes and a therapeutic target for the treatment of FXS cognitive impairment.

GCs and MCs are two excitatory cell types of the DG. The GC bodies form the granule cell layer, while the MCs are located only in hilus and are the most common cells in polymorphic layer (Amaral et al., 2007). MCs excite or inhibit GCs through direct 
inputs (Soriano and Frotscher, 1994) or interneuron activation (Scharfman, 1995), and precede GCs in detecting changes and help to expand the range of GC pattern separation (Jung et al., 2019). The understanding of MCs in DG function is limited, but their contributions to behavior have been proposed, including to memory, novelty, and anxiety (Scharfman, 2016). It is still unclear whether MCs are involved in the spine dysgenesis and pathophysiology in FXS. Our results indicated that both GCs and MCs were transfected, with a relative rate of $1.32 \pm 0.15$. After ICAM5 intervention, the sEPSC amplitude was increased in Fmr1 KO GCs, probably induced by direct dendritic spine maturation or by the enhanced excited inputs from MCs. Furthermore, ICAM5 intervention in MCs could also contribute to the reversed behavior disorder in $\mathrm{KO}$ mice. However, the proportional contribution for GCs and MCs is still unknown. Future experiments using cell type-specific inactivation might directly test MC contribution to FXS.

In summary, our results suggest that ICAM5 is an mRNA target of FMRP and plays a critical role in the spine dysgenesis and pathophysiology of FXS. FMRP could regulate translational events involved in the synthesis of ICAM5 probably via direct binding and concomitantly influences dendritic spine development and disease severity. Genetic ICAM5 intervention attenuated behavioral deficits in Fmrl $\mathrm{KO}$ mice, which may provide therapeutic benefits in the treatment of FXS cognitive impairment and other NDDs.

\section{References}

Amaral DG, Scharfman HE, Lavenex P (2007) The dentate gyrus: fundamental neuroanatomical organization (dentate gyrus for dummies). Prog Brain Res 163:3-22.

Antar LN, Dictenberg JB, Plociniak M, Afroz R, Bassell GJ (2005) Localization of FMRP-associated mRNA granules and requirement of microtubules for activity-dependent trafficking in hippocampal neurons. Genes Brain Behav 4:350-359.

Ascano M Jr, Mukherjee N, Bandaru P, Miller JB, Nusbaum JD, Corcoran DL, Langlois C, Munschauer M, Dewell S, Hafner M, Williams Z, Ohler U, Tuschl T (2012) FMRP targets distinct mRNA sequence elements to regulate protein expression. Nature 492:382-386.

Bailey TL, Boden M, Buske FA, Frith M, Grant CE, Clementi L, Noble WS (2009) MEME SUITE: tools for motif discovery and searching. Nucleic Acids Res 37(Web Server issue):W202-W208.

Baker KB, Wray SP, Ritter R, Mason S, Lanthorn TH, Savelieva KV (2010) Male and female Fmr1 knockout mice on C57 albino background exhibit spatial learning and memory impairments. Genes Brain Behav 9:562-574.

Bassell GJ, Warren ST (2008) Fragile X syndrome: loss of local mRNA regulation alters synaptic development and function. Neuron 60:201-214.

Bourgeron T (2009) A synaptic trek to autism. Curr Opin Neurobiol 19: 231-234.

Brown V, Huynh M (2001) Interactive CD-ROM: making learning easier. Collegian 8:ii-iv.

Calabrese B, Wilson MS, Halpain S (2006) Development and regulation of dendritic spine synapses. Physiology 21:38-47.

Chang HK, Kim KH, Kang KW, Kang YJ, Kim TW, Park HK, Kim SE, Kim CJ (2015) Antidepressants modulate glycine action in rat hippocampus. J Exerc Rehabil 11:311-319.

Cheng C, Trzcinski O, Doering LC (2014) Fluorescent labeling of dendritic spines in cell cultures with the carbocyanine dye "Dil". Front Neuroanat 8:30.

Chen QY, Li J, Sun H, Wu F, Zhu Y, Kluz T, Jordan A, DesMarais T, Zhang X, Murphy A, Costa M (2018) Role of miR-31 and SATB2 in arsenicinduced malignant BEAS-2B cell transformation. Mol Carcinog 57: 968-977.

Chin-Wei H, Yi-Jung H, Jing-Jane T, Chao-Ching H (2006) Effects of lamotrigine on field potentials, propagation, and long-term potentiation in rat prefrontal cortex in multi-electrode recording. J Neurosci Res 83:1141-1150.

Conant K, Lonskaya I, Szklarczyk A, Krall C, Steiner J, Maguire-Zeiss K, Lim ST (2011) Methamphetamine-associated cleavage of the synaptic adhesion molecule intercellular adhesion molecule-5. J Neurochem 118:521-532.
Darnell JC, Klann E (2013) The translation of translational control by FMRP: therapeutic targets for FXS. Nat Neurosci 16:1530-1536.

Darnell JC, Van Driesche SJ, Zhang C, Hung KY, Mele A, Fraser CE, Stone EF, Chen C, Chi SW, Licatalosi DD, Richter JD, Darnell RB (2011) FMRP stalls ribosomal translocation on mRNAs linked to synaptic function and autism. Cell 146:247-261.

Darnell RB (2010) HITS-CLIP: panoramic views of protein-RNA regulation in living cells. Wiley Interdiscip Rev RNA 1:266-286.

Davis JK, Broadie K (2017) Multifarious functions of the fragile X mental retardation protein. Trends Genet 33:703-714.

De Rubeis S, Fernández E, Buzzi A, Di Marino D, Bagni C (2012) Molecular and cellular aspects of mental retardation in the fragile $\mathrm{X}$ syndrome: from gene mutation/s to spine dysmorphogenesis. Adv Exp Med Biol 970:517-551.

Furutani Y, Matsuno H, Kawasaki M, Sasaki T, Mori K, Yoshihara Y (2007) Interaction between telencephalin and ERM family proteins mediates dendritic filopodia formation. J Neurosci 27:8866-8876.

Gao L, Tian M, Zhao HY, Xu QQ, Huang YM, Si QC, Tian Q, Wu QM, Hu XM, Sun LB, McClintock SM, Zeng Y (2016) TrkB activation by 7 , 8-dihydroxyflavone increases synapse AMPA subunits and ameliorates spatial memory deficits in a mouse model of Alzheimer's disease. J Neurochem 136:620-636.

Gupta S, Stamatoyannopoulos JA, Bailey TL, Noble WS (2007) Quantifying similarity between motifs. Genome Biol 8:R24.

Hinds HL, Ashley CT, Sutcliffe JS, Nelson DL, Warren ST, Housman DE, Schalling M (1993) Tissue specific expression of FMR-1 provides evidence for a functional role in fragile X syndrome. Nat Genet 3:36-43.

Hou L, Antion MD, Hu D, Spencer CM, Paylor R, Klann E (2006) Dynamic translational and proteasomal regulation of fragile $\mathrm{X}$ mental retardation protein controls mGluR-dependent long-term depression. Neuron 51: $441-454$.

Hozumi Y, Ito T, Nakano T, Nakagawa T, Aoyagi M, Kondo H, Goto K (2003) Nuclear localization of diacylglycerol kinase zeta in neurons. Eur J Neurosci 18:1448-1457.

Irwin SA, Patel B, Idupulapati M, Harris JB, Crisostomo RA, Larsen BP, Kooy F, Willems PJ, Cras P, Kozlowski PB, Swain RA, Weiler IJ, Greenough WT (2001) Abnormal dendritic spine characteristics in the temporal and visual cortices of patients with fragile-X syndrome: a quantitative examination. Am J Med Genet 98:161-167.

Jung D, Kim S, Sariev A, Sharif F, Kim D, Royer S (2019) Dentate granule and mossy cells exhibit distinct spatiotemporal responses to local change in a one-dimensional landscape of visual-tactile cues. Sci Rep 9:9545.

Kao DI, Aldridge GM, Weiler IJ, Greenough WT (2010) Altered mRNA transport, docking, and protein translation in neurons lacking fragile $\mathrm{X}$ mental retardation protein. Proc Natl Acad Sci U S A 107:15601-15606.

Larson J, Jessen RE, Kim D, Fine AK, du Hoffmann J (2005) Age-dependent and selective impairment of long-term potentiation in the anterior piriform cortex of mice lacking the fragile $\mathrm{X}$ mental retardation protein. J Neurosci 25:9460-9469.

Li J, Pelletier MR, Perez Velazquez JL, Carlen PL (2002) Reduced cortical synaptic plasticity and GluR1 expression associated with fragile X mental retardation protein deficiency. Mol Cell Neurosci 19:138-151.

Lu R, Wang H, Liang Z, Ku L, O'donnell WT, Li W, Warren ST, Feng Y (2004) The fragile $\mathrm{X}$ protein controls microtubule-associated protein $1 \mathrm{~B}$ translation and microtubule stability in brain neuron development. Proc Natl Acad Sci U S A 101:15201-15206.

Matsuno H, Okabe S, Mishina M, Yanagida T, Mori K, Yoshihara Y (2006) Telencephalin slows spine maturation. J Neurosci 26:1776-1786.

McMahon AC, Rosbash M (2016) Promiscuous or discriminating: has the favored mRNA target of fragile $\mathrm{X}$ mental retardation protein been overlooked? Proc Natl Acad Sci U S A 113:7009-7011.

Melko M, Bardoni B (2010) The role of G-quadruplex in RNA metabolism: involvement of FMRP and FMR2P. Biochimie 92:919-926.

Mitsui S, Saito M, Mori K, Yoshihara Y (2007) A transcriptional enhancer that directs telencephalon-specific transgene expression in mouse brain. Cereb Cortex 17:522-530.

Mizuno T, Yoshihara Y, Inazawa J, Kagamiyama H, Mori K (1997) cDNA cloning and chromosomal localization of the human telencephalin and its distinctive interaction with lymphocyte function-associated antigen-1. J Biol Chem 272:1156-1163.

Moradi F, Berglund P, Linnskog R, Leandersson K, Andersson T, Prasad CP (2016) Dual mechanisms of action of the RNA-binding protein human 
antigen $\mathrm{R}$ explains its regulatory effect on melanoma cell migration. Transl Res 172:45-60.

Mori K, Fujita SC, Watanabe Y, Obata K, Hayaishi O (1987) Telencephalonspecific antigen identified by monoclonal antibody. Proc Natl Acad Sci U S A 84:3921-3925.

Nakamura K, Manabe T, Watanabe M, Mamiya T, Ichikawa R, Kiyama Y, Sanbo M, Yagi T, Inoue Y, Nabeshima T, Mori H, Mishina M (2001) Enhancement of hippocampal LTP, reference memory and sensorimotor gating in mutant mice lacking a telencephalon-specific cell adhesion molecule. Eur J Neurosci 13:179-189.

Niedringhaus M, Chen X, Dzakpasu R, Conant K (2012) MMPs and soluble ICAM-5 increase neuronal excitability within in vitro networks of hippocampal neurons. PLoS One 7:e42631.

Ning L, Tian L, Smirnov S, Vihinen H, Llano O, Vick K, Davis RL, Rivera C, Gahmberg CG (2013) Interactions between ICAM-5 and $\beta 1$ integrins regulate neuronal synapse formation. J Cell Sci 126:77-89.

Oka S, Mori K, Watanabe Y (1990) Mammalian telencephalic neurons express a segment-specific membrane glycoprotein, telencephalin. Neuroscience 35:93-103.

Pasciuto E, Bagni C (2014) SnapShot: FMRP mRNA targets and diseases. Cell 158:1446-1446.e1.

Penzes P, Cahill ME, Jones KA, VanLeeuwen JE, Woolfrey KM (2011) Dendritic spine pathology in neuropsychiatric disorders. Nat Neurosci 14:285-293.

Portera Cailliau C, Yuste R (2001) On the function of dendritic filopodia [in Spanish]. Rev Neurol 33:1158-1166.

Raemaekers T, Peric A, Baatsen P, Sannerud R, Declerck I, Baert V, Michiels C, Annaert W (2012) ARF6-mediated endosomal transport of telencephalin affects dendritic filopodia-to-spine maturation. EMBO J 31:3252-3269.

Recacha R, Jiménez D, Tian L, Barredo R, Gahmberg CG, Casasnovas JM (2014) Crystal structures of an ICAM-5 ectodomain fragment show electrostatic-based homophilic adhesions. Acta Crystallogr D Biol Crystallogr 70:1934-1943.

Scharfman HE (1995) Electrophysiological evidence that dentate hilar mossy cells are excitatory and innervate both granule cells and interneurons. J Neurophysiol 74:179-194.

Scharfman HE (2016) The enigmatic mossy cell of the dentate gyrus. Nat Rev Neurosci 17:562-575.

Soriano E, Frotscher M (1994) Mossy cells of the rat fascia dentata are glutamate-immunoreactive. Hippocampus 4:65-69.

Specchia V, D'Attis S, Puricella A, Bozzetti MP (2017) dFmrl plays roles in small RNA pathways of Drosophila melanogaster. Int J Mol Sci 18:E1066.
Spencer CM, Alekseyenko O, Serysheva E, Yuva-Paylor LA, Paylor R (2005) Altered anxiety-related and social behaviors in the Fmr1 knockout mouse model of fragile X syndrome. Genes Brain Behav 4:420-430.

Tabuchi K, Blundell J, Etherton MR, Hammer RE, Liu X, Powell CM, Südhof TC (2007) A neuroligin-3 mutation implicated in autism increases inhibitory synaptic transmission in mice. Science 318:71-76.

Tian L, Nyman H, Kilgannon P, Yoshihara Y, Mori K, Andersson LC, Kaukinen S, Rauvala H, Gallatin WM, Gahmberg CG (2000) Intercellular adhesion molecule- 5 induces dendritic outgrowth by homophilic adhesion. J Cell Biol 150:243-252.

Tian M, Zeng Y, Hu Y, Yuan X, Liu S, Li J, Lu P, Sun Y, Gao L, Fu D, Li Y, Wang S, McClintock SM (2015) 7, 8-dihydroxyflavone induces synapse expression of AMPA GluAl and ameliorates cognitive and spine abnormalities in a mouse model of fragile X syndrome. Neuropharmacology 89:43-53.

Wang T, Bray SM, Warren ST (2012) New perspectives on the biology of fragile X syndrome. Curr Opin Genet Dev 22:256-263.

Wijetunge DS, Karunathilake KH, Chaudhari A, Katani R, Dudley EG, Kapur V, Kariyawasam S (2014) Complete nucleotide sequence of pRS218, a large virulence plasmid that augments pathogenic potential of meningitisassociated Escherichia coli strain RS218. BMC Microbiol 14:2003.

Yang H (2012) Structure, expression, and function of ICAM-5. Comp Funct Genomics 2012:368938.

Yoshihara Y, Mori K (1994) Telencephalin: a neuronal area code molecule? Neurosci Res 21:119-124.

Yoshihara Y, Oka S, Nemoto Y, Watanabe Y, Nagata S, Kagamiyama H, Mori K (1994) An ICAM-related neuronal glycoprotein, telencephalin, with brain segment-specific expression. Neuron 12:541-543.

Zalfa F, Eleuteri B, Dickson KS, Mercaldo V, De RS, Di PA, Grant SG (2007) A new function for the fragile $\mathrm{X}$ mental retardation protein in regulation of PSD-95 mRNA stability. Nat Neurosci 10:578-587.

Zancada-Menendez C, Alvarez-Suarez P, Sampedro-Piquero P, Cuesta M, Begega A (2017) Requiring collaboration: hippocampal-prefrontal networks needed in spatial working memory and ageing. A multivariate analysis approach. Neurobiol Learn Mem 140:33-42.

Zeng Y, Liu Y, Wu M, Liu J, Hu Q (2012) Activation of TrkB by 7,8dihydroxyflavone prevents fear memory defects and facilitates amygdalar synaptic plasticity in aging. J Alzheimers Dis 31:765-778.

Zhang P, Abdelmohsen K, Liu Y, Tominaga-Yamanaka K, Yoon JH, Ioannis G, Martindale JL, Zhang Y, Becker KG, Yang IH, Gorospe M, Mattson MP (2015) Novel RNA- and FMRP-binding protein TRF2-S regulates axonal mRNA transport and presynaptic plasticity. Nat Commun 6:8888. 